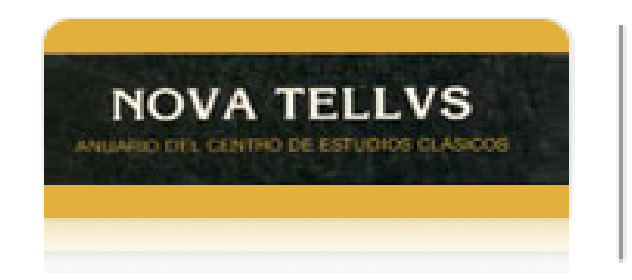

Nova Tellus

ISSN: 0185-3058

novatelu@servidor.unam.mx

Centro de Estudios Clásicos

México

Ramírez Vidal, Gerardo

Algunas quaestiones sobre el diálogo socrático a partir de Livio Rossetti

Nova Tellus, vol. 30, núm. 2, 2012, pp. 241-276

Centro de Estudios Clásicos

Distrito Federal, México

Disponible en: http://www.redalyc.org/articulo.oa?id=59128313012

- Cómo citar el artículo

- Número completo

- Más información del artículo

Página de la revista en redalyc.org

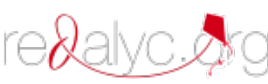

Sistema de Información Científica

Red de Revistas Científicas de América Latina, el Caribe, España y Portugal

Proyecto académico sin fines de lucro, desarrollado bajo la iniciativa de acceso abierto 


\title{
Algunas quaestiones sobre el diálogo socrático a partir de Livio Rossetti
}

\author{
Gerardo RAMíREZ VIDAL \\ Universidad Nacional Autónoma de México \\ grvidal18@gmail.com
}

Desde hace cuarenta años Livio Rossetti ha tratado de entender los difíciles y fascinantes problemas relacionados con el diálogo socrático desde una perspectiva diferente de y en buena medida opuesta a los métodos tradicionales. Para entender lo anterior tal vez sea útil observar el desarrollo de sus indagaciones. Los ensayos publicados en este periodo parecen responder en su conjunto a una planeación a largo plazo. Los trabajos de los primeros catorce años (de 1971 a 1984) intentan sobre todo reflexionar acerca del estado de la cuestión al respecto, ${ }^{1}$ establecer el corpus de estudio sobre Sócrates y la escuela socrática ${ }^{2}$ e identificar los principales problemas relativos a la literatura socrática. ${ }^{3}$ Luego, traslapados con esa primera etapa, los ensayos de los siguientes quince años (de 1984 a 1998) se proponen principalmente refutar la tendencia, muy enraizada en los estudios modernos, a considerar a los sofistas más como maestros de retórica que como filósofos o pensadores serios. Se observa, por un lado, el uso magistral que Sócrates y Platón hacen de artilugios retóricos y, por otro, la seriedad de los planteamientos de los "sofistas". 4 Al lado de lo anterior, se analiza una serie de recursos macro-retóricos presentes en los diálogos, en particular los platónicos, ${ }^{5}$ a la par de de-

${ }^{1}$ Este periodo iniciaría con un texto publicado en 1971, cuyo título es muy sugerente: "Recenti sviluppi della questione socratica", donde nuestro autor presenta el estado de la cuestión, como si se estuviera preparando para llevar a cabo la investigación sobre el tema.

${ }^{2}$ En particular me refiero a los tres artículos publicados bajo el título "Alla ricerca dei logoi Sokratikoi perduti” de 1974 (cf. infra, p. 278), 1975a y 1975b, además de otros posteriores que pueden incluirse en esta línea de investigación, como los de 1991 y 1993.

${ }^{3}$ Cf. sobre todo los Aspetti della letteratura socratica antica de 1977 y La 'questione socratica': un problema malposto de 1983. El periodo concluiría con su exposición "Socrate e le scuole socratiche minori", publicada en el vol. XXXII de la Grande antologia filosofica (1984), aunque obviamente esta línea de investigación continuó en años posteriores.

${ }^{4}$ Característico de esta etapa es el artículo sobre la retórica de los sofistas y la de Sócrates, publicado en 1984, y otros ensayos sobre la retórica de Sócrates, en particular sobre el Eutifrón de Platón. En cuanto a los sofistas, cf. también Rossetti, 1985.

${ }^{5}$ Los resultados teóricos de los estudios prácticos de los expedientes retóricos confluyen en su libro Strategie macro-retoriche, de 1994, obra que sirve como herramienta 
sarrollar con base en la tecnología digital un proyecto sobre el diálogo interactivo.

En fin, los estudios publicados durante los catorce años siguientes (de 1998 a 2011) se orientan, por una parte, sobre todo a describir la naturaleza, los elementos y el funcionamiento de los diálogos y, por otra, a mostrar su importancia como género filosófico de primer orden en las primeras tres décadas del siglo IV a. C. ${ }^{6}$ Se tiene la impresión de que estos últimos artículos cierran un gran ciclo de tesis, antítesis y síntesis o, mejor, de proemio, agón y epílogo, aunque es necesario observar que los temas se traslapan en buena medida y que, en fin, las fechas de publicación no responden del todo a la ideación y escritura de los textos.

Los trabajos de la compilación objeto de este comentario, Le Dialogue socratique, pertenecen sobre todo a esta última etapa, aun cuando algunos de ellos se publicaron antes. ${ }^{7}$ Nos encontramos, pues, en la culminación de un enorme esfuerzo por entender ese género. Las consideraciones del propio autor son certeras:

[el libro] me permite mostrar más nítidamente que en el pasado el hilo conductor de muchas de mis investigaciones, como son: (a) la idea de que Sócrates sea identificado no por algunas doctrinas en particular sino por un modo altamente innovador de "trabajar sobre los" y con los interlocutores (cf. la expresión "to do things with words"); (b) el intento de entender lo que ha caracterizado a la literatura socrática más antigua, en qué cosa consiste su peculiar identidad, cuáles son las raíces de su aparentemente vitalidad indeleble. ${ }^{8}$

sistemática de los ensayos incluidos en el volumen en comento. Esta etapa concluiría con el ensayo de 1998a: " "Rhétorique de l'anti-rhétorique' et effet de surprise...”.

${ }^{6}$ Por ejemplo, Rossetti 1998b y 1998c, donde se encuentran propuestas de análisis sobre el texto filosófico; Rossetti 2010a, y el texto publicado Rossetti-Stavru 2010e.

${ }^{7}$ El ensayo más antiguo apareció en 1995 (Cap. 4) y el más reciente en 2010 (Cap. 8). El primero de ambos, dedicado al Eutifrón de Platón, aunque en buena medida es un producto de la segunda etapa, de carácter agonístico, anuncia al mismo tiempo esa visión epilogal sobre el diálogo socrático. Reitero que, a menudo, las fechas de publicación no coinciden necesariamente con las de ideación y escritura. Por ejemplo, "L'Euthydème de Xénophon" (Cap. 2) fue publicado en 2007, pero fue ideado más de una década antes, en 1993. A veces son tópicos recurrentes. Es el caso de la retórica de Sócrates, de 2001 (Cap. 6): un primer artículo fue publicado en 1989 y otro en 2001, con el mismo título; el mismo tema aparece también en 1990.

8 www.rossettiweb.it/livio/index.php? content=Bibliografia\%202010-, consultado el 15 de octubre de 2012. 
Considero que el valor del libro radica sobre todo en esos dos filones conclusivos de cuarenta años de trabajo sobre el diálogo socrático: su innovación comunicativa y su singularidad como género literario.

Si se quisiera describir las características generales de la producción reseñada sería suficiente con recurrir al Prólogo escrito por F. Roustang, el compilador de los ensayos, quien considera que la singularidad más llamativa de nuestro autor es su carácter "poco ordinario", cuya "impertinencia" hizo irrupción en un medio tan rígido como el de los estudios socráticos, y cuyas lecturas resultan muy diferentes de aquellas a las que estamos tan habituados. ${ }^{9}$ En su ensayo sobre Eutifrón (Cap. 4), el maestro perusino adivina una objeción a su propia interpretación sobre la pretensión de Sócrates y Platón de manipular a sus lectores:

¿Qué es esto: ¿una escuela de antiplatonismo y antisocratismo? ¿Una invitación a desconfiar, rechazar y, en fin degradar a ambos personajes? ¿Un intento por rehabilitar a los sofistas sin preocuparse de estar desacreditando a sus más duros detractores? (p. 179).

Luego niega que lo anterior sea así. De cualquier modo, aunque sus lecturas rechazan tajantemente las interpretaciones más acreditadas al respecto, considero que su supuesto antiplatonismo y antisocratismo no lo es en contra de ambos filósofos (iqué culpa tienen ellos!), sino contra los modelos canónicos de interpretar los diálogos, además de que sus reclamos constituyen una llamada de atención a los estudiosos del socratismo con el fin de que reconsideren la crítica tradicional y busquen nuevas respuestas a las múltiples cuestiones planteadas por los diálogos. Con este propósito, el propio autor recurre a una prosopopeya de sí mismo: "Livio Rossetti nos alerta sobre la necesidad de desconfiar de Platón. Tal vez él no tiene confianza ni en sí mismo, ni en los recursos de los comentadores y, de forma general, de la comunidad científica" (pp. 260-261). Es cierto: Rossetti desconfía de los comentadores y sobre todo de los exégetas contemporáneos. ${ }^{10}$

${ }^{9}$ Roustang 2011, p. 17; cf. infra, p. 289.

${ }^{10}$ Es claro que refuta el modelo analítico, el cual tiene la pretensión de aislar los argumentos y observarlos en su desnudez, haciendo caso omiso de todo lo demás: el contexto y los elementos dialógicos, como si éstos no tuvieran nada que ver con la actividad hermenéutica. También rechaza la interpretación de la escuela de Tubinga y Milán basada en la idea de que Platón encubre o esconde los principales puntos de su doctrina 
A mi juicio, la compilación aquí comentada, al lado de planteamientos que podríamos llamar "antilógicos" o agonísticos, ${ }^{11}$ presenta también ideas firmes y serenas, gracias al largo periodo de refutación de las tesis más difundidas sobre los diálogos. Para nuestro autor estas producciones literarias no constituyen una producción aséptica, objetiva y desinteresada, sino que reflejan la exigencia de los socráticos de defender la memoria y la herencia de Sócrates con el propósito tanto de afirmar la originalidad del maestro frente a otros intelectuales prestigiados, como de divulgar la superioridad de la enseñanza que los autores de diálogos impartían en sus escuelas. Para lograr lo anterior recurrían a la imitación o reproducción de la conversación real que el maestro acostumbraba sostener en vida y que los propios alumnos habían aprendido a reproducir en la práctica cotidiana. Las producciones literarias así concebidas representaron en su momento una gran novedad.

Teniendo en consideración esta orientación general sobre la obra de Livio Rossetti y de este libro en particular, en las siguientes páginas me propongo presentar un sumario de las principales aportaciones de Le Dialogue socratique que considero deben ser patrimonio común de los estudiosos de la filosofía antigua. En primer lugar, describiré las nociones generales que permiten entender cabalmente qué es y qué representa el diálogo socrático (pp. 245-253). En seguida, me referiré al instrumento metodológico (la "macro-retórica") que el estudioso ha diseñado

esotérica mediante una serie amplia de recursos dialógicos. Más bien, afirma Rossetti, "lo que escribe Platón aprovecha mecanismos de protección muy amplios, cuya función es orientar [...] la atención del lector, hacerle comprender todo" o "sólo una parte", etcétera (p. 258). También se opone a la importancia que los estudiosos estadounidenses dan al papel que juega el cuadro narrativo de cada diálogo, en el que con frecuencia encuentran el sentido del texto, pues se trata de un procedimiento muy limitado que no considera la riqueza de elementos que entran en acción. Por último, sobre las propuesta de lectura de Th. A. Szlezák, indica (p. 262) que ésta "encuentra su límite en el hecho de alertar sólo sobre la pretendida estructura esotérica del diálogo [...] y de denunciar el pretendido malentendido de muchas generaciones de comentadores que no logran superar la letra para llegar precisamente a ese nivel" del sentido esotérico, esto es, de la doctrina oculta de Platón. Para llegar a la doctrina o a las ideas de Platón, insiste Rossetti, es imprescindible tomar en consideración primero los elementos de ocultamiento de los verdaderos intereses del filósofo y preguntarse sobre lo que realmente quiere comunicar de manera indirecta o alusiva.

${ }^{11}$ Cf. sobre todo las pp. 256-262 (Cap. 7, ensayo original de 1997). 
para el análisis del diálogo (pp. 253-263). En tercer lugar, expondré las aportaciones del libro de manera específica en el caso de los diálogos platónicos (pp. 263-269). Por último, comentaré una de las hipótesis más llamativas del libro: la autoidentificación de Sócrates y sus discípulos como miembros del grupo de los "filósofos", claramente identificados y diferenciados de otros pensadores o maestros de escuela, en particular de los sofistas (pp. 270-276).

\section{El diálogo socrático}

\section{Definición de "diálogo socrático". Para nuestro autor,}

el diálogo socrático puede ser descrito, en general, como una especie de drama a medio camino entre la tragedia y la comedia, ya no versificado ni destinado a formas solemnes de representación pública sino reservado a la lectura privada o cuando más a sesiones durante las cuales, probablemente, uno o más lectores-actores se ponían a recrear en voz alta [...] un diálogo escrito por un socrático (p. 126). ${ }^{12}$

El estudioso emplea varios criterios de definición: género (una especie de drama), forma (prosa), medio (lectura privada) y función (el propósito es dar vida a una manera de ser o conducta ejemplar, la de Sócrates, en su actividad dialéctica, digna de ser imitada por el público al que está dirigida la obra). Los tres últimos sirven para diferenciar al diálogo socrático de los demás tipos de dramas. Además, agrega otro distintivo: se trata de una forma original de renovar la práctica de la comedia, ahora con personajes reales muy conocidos que dialogan en un ambiente más o menos actual o reciente.

Rossetti va más allá de la simple constatación del género y de las diferencias del diálogo frente a las demás especies de drama. Define lo propio y permanente del diálogo socrático en sí, lo cual — diría yo-

${ }^{12}$ Cf. la definición de Diógenes Laercio III.48: "Diálogo es un discurso compuesto de pregunta y respuesta acerca de un asunto filosófico y político con la debida caracterización de las personas que intervienen y su exposición de acuerdo con el estilo"

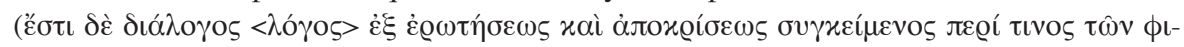

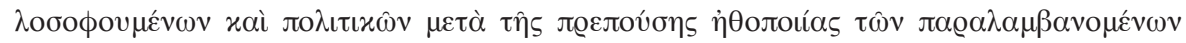

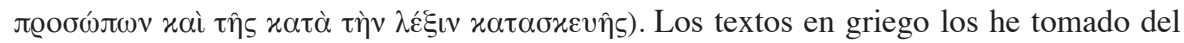
Thesaurus Linguae Graecae (TLG). A Digital Library of Greek Literature, University of California, Irvine, 1912, cotejados con ediciones autorizadas. 
lo separa de todas las demás especies de productos literarios. Para ello, distingue los elementos permanentes de los accidentales. Muestra entonces que las doctrinas atribuidas a Sócrates y el desarrollo preciso de algún encuentro son componentes contingentes; en cambio, son característicos del arte del dialogar socrático, entre otros, el gusto por las analogías triviales, la pasión por los contraejemplos, la creación de una atmósfera que permita llevar el diálogo adelante, el gusto por los discursos breves, (pp. 133-134), o las secuencias discursivas que permiten presuponer un plan de elaboración premeditado. Estos últimos aspectos constituyen mecanismos de comunicación eficaces, de estrategias discursivas que el autor engloba bajo el término de "macro-retórica". Así, la peculiaridad atípica del maestro primero y luego del diálogo socrático en general radicaría en las estrategias señaladas, y "consistirá más en construir provocaciones intelectuales elaboradas ad personam que a consagrarse a la fijación dogmática de una doctrina bien identificada" (p. 275).

De tal manera, el arte dialéctico de Sócrates, reconocible en los diferentes testimonios dialógicos y no identificable en ningún otro personaje, sería esa forma de desestabilizar y de abordar a los interlocutores, de conducirlos por un camino establecido de antemano y de despistarlos, confundirlos o hacerlos regresar al punto de partida una y otra vez. Por si fuera poco, no se trataría de una simple práctica, sino de una técnica reglamentada, artificial, elaborada por Sócrates y continuada por sus discípulos, quienes a la postre la reprodujeron por escrito, no sin introducir cada uno de ellos cambios significativos, aunque de carácter accesorio. ${ }^{13}$ En suma, lo propio del estilo socrático no es el contenido o las ideas, sino el modo de discutir muy característico de Sócrates y sus discípulos.

Considero que la hipótesis anterior es la más revolucionaria de todas las expuestas en el libro y, al mismo tiempo, la más riesgosa, pues reduce la filosofía socrática a una simple estrategia comunicativa, a una técnica de manipulación, a un juego de palabras y a un método desprovisto de ideas y falto de contenido, dirigido más al escarnio de los interlocutores que a la búsqueda del conocimiento. Echa por tierra todo aquello que ha sido considerado como el elemento distintivo y la nota de mayor orgullo de la filosofía socrática, en particular, y la occidental en general.

${ }^{13}$ Los autores de diálogos introdujeron cambios o los inventaron, de modo que los diálogos que leemos son piezas dramáticas donde se representa la costumbre socrática de discutir, pero son ficticios en grados diferentes. Véase también Rossetti 2004. 
En este punto es necesario subrayar la diferencia entre diálogo pronunciado y diálogo escrito. En el primer caso, dos interlocutores reales dialogan sobre un asunto y un público más o menos amplio que escucha el intercambio verbal; Sócrates habría establecido y practicado los procedimientos discursivos ante sus discípulos y otros jóvenes quienes a su vez imitaban esa forma de dialogar. En el segundo, un autor elabora una recreación de un diálogo para que un lector la lea o recite a un cierto número de oyentes. Se debe tener cuidado en no confundir el diálogo verdadero con la recreación en gran medida ficticia.

2. El desarrollo histórico del diálogo y los autores. En cuanto a los antecedentes del diálogo socrático, se puede constatar, siguiendo a Rossetti, que no se encuentran ejemplos ni siquiera rastros de textos en la literatura anterior a la emergencia del diálogo que pudieran tener algún parecido con ese nuevo género. La comedia y el mimo tampoco presentan elementos importantes que puedan compararse a los del diálogo. Por lo tanto, se trata de un género literario y filosófico por completo novedoso del cual pueden describirse con relativa claridad las diferentes etapas de su desarrollo: nacimiento, florecimiento y decadencia, además de identificarse a sus autores.

El proceso de "estandarización" de ese tipo de obras se dio al interior del grupo socrático, y se debió al propio maestro, un personaje singular que inauguró maneras inéditas y características de esa forma de conversar o discutir (pp. 42-43), y enseñó la representación de esa actividad a sus discípulos, quienes adquirieron, aún en vida del maestro y a instancias de él, una formación en la composición, escritura e inclusive en la publicación de diálogos. ${ }^{14}$ Le Dialogue socratique documenta la costumbre del propio Sócrates y de sus discípulos de relatar o reproducir oralmente o por escrito (en el caso de los segundos) diálogos de encuentros memorables ocurridos poco o mucho tiempo antes (pp. 45-49). Entre los pasajes significativos que muestran ese proceso de enseñanza del arte de discutir, ${ }^{15}$ el caso de Aristipo (Cap. 3) es el más elocuen-

${ }^{14}$ En esta primera etapa de la historia del diálogo socrático - que abarcaría aproximadamente los diez últimos años de la vida del maestro-, se habría creado el modelo refutativo (elenkhetikós).

15 Cf. pp. 42-43, 104-119 y 204-209. Los pasajes son: X. Mem. III.8.1-13 (sobre Aristipo); Mem. IV.2 (sobre los efectos que provocaban las conversaciones de Sócrates en su interlocutor); P1. Ap. 29d-6-7 (Sócrates mismo recuerda sus palabras habituales); 
te: ${ }^{16}$ el joven discípulo creyó haber adquirido la suficiente preparación para poner en práctica las lecciones aprendidas con el maestro y lo hizo así, pero para ello eligió ponerse a prueba interrogando al propio Sócrates, sufriendo un fracaso mayúsculo, pues su experto interlocutor anuló con facilidad las jugadas que él había planeado. El caso del zapatero Simón es digno del mayor interés: tenía ese discípulo del filósofo la costumbre de "tomar notas sobre los encuentros con Sócrates para ponerlos él mismo en forma en una simulación escrita” (p. 46). Otra fuente (Arist. Fr. 72 Rose) testimonia que Alexámenos de Teos fue el heuretês o el primero en haber escrito diálogos socráticos. Los casos anteriores muestran que la técnica de elaboración dialógica y su enseñanza se deben al propio Sócrates, lo cual constituye el nacimiento del género dialógico.

El diálogo alcanzó su apogeo durante el primer cuarto o los primeros 30 años del siglo IV. Entre las causas de su amplia difusión se encuentra la controversia que tuvo lugar, después de muerto el maestro, entre quienes justificaban su condena, que eran los menos, y quienes recreaban la vida del maestro para reafirmar su adhesión doctrinaria genuina, teniendo a la vista el interés que aquél despertaba en amplias capas de la población. ${ }^{17} \mathrm{El}$ proceso de Sócrates y su muerte ofrecieron a los antiguos discípulos una excelente oportunidad para elaborar diálogos, actividad a la que ya estaban acostumbrados, pero ahora con la finalidad - entre otras - de explicar su propia conducta ante los acontecimientoa referidos (pp. 49-50).

Por lo tanto, la práctica oral del diálogo (reglamentada, artificial, tecnificada) debe atribuirse al propio Sócrates; en cambio, la imitación oral y escrita (las piezas "dramáticas") fue obra de una docena de sus discípulos. Poco antes se ha mencionado a Alexámenos de Teos como el primer discípulo en haber escrito diálogos. Después de él otros recurrieron a esa estrategia dialógica. Algunos de éstos llegaron a ser jefes de escuela: Antístenes (cinismo), Aristipo (escuela cirenaica), Euclides (escuela

P1. Ap. 23c (sobre los jóvenes que imitan el modo de dialogar socrático) y 33b-c (el interrogatorio de quienes pretenden ser expertos); Grg. 447c-d (donde se presenta al maestro Sócrates dando indicaciones a Querefón de cómo interrogar a Gorgias); Plut. De curiositate 2.516c (Iscómaco reproduce a Aristipo ejemplos de logoi socráticos).

${ }^{16}$ Cf. además, pp. 104 y 204-205.

${ }^{17}$ Cf. pp. 52 y 121-123. 
megárica), Fedón de Elis (de la escuela de Élide) y Platón (Academia), además de dos escritores importantes: Esquines de Esfeto y Jenofonte, a quienes se debe agregar los llamados "socráticos menores": Critón, Glaucón, Simias y Simón el zapatero (pp. 27 y 125, n. 2).

El ocaso del diálogo socrático se verificó a mediados del siglo IV en un lento proceso que significó su modificación y final sustitución por otro tipo de discurso filosófico. Sin embargo, ese género no desapareció por completo, si se toma en consideración que el número de diálogos posteriores a la muerte de Platón representan menos del $10 \%$ del total (p. 31), lo cual no es poco.

En suma, me permito suponer que, durante los 25 años después de la muerte del maestro, sus discípulos "directos" (p. 125) continuaron utilizando ese modelo de formación discursiva. Esto pudo suceder, por ejemplo, dentro de la Academia de Platón. El propio Aristóteles parece testimoniarlo en los Tópicos donde alude con frecuencia a los participantes del diálogo: el interrogador y sus interlocutores. Al mismo tiempo, se generalizó la costumbre de escribir diálogos. ${ }^{18}$ Posteriormente, el interés en el intercambio oral y en su recreación por escrito fue disminuyendo de manera paulatina hasta ser sustituido por otros modelos, como la exposición al estilo aristotélico, aproximadamente a la muerte del último de ellos, que fue precisamente Platón (347 a. C.). Desde mi punto de vista, otro de los motivos del florecimiento de los diálogos socráticos fue el extendido debate entre las diversas escuelas de educación superior, en la que se veían involucrados tanto los discípulos de Sócrates (entre ellos Platón) como los maestros de política, los logógrafos y los escritores de artes, a todos los cuales el Divino filósofo denominaba "sofistas", tratándolos como embaucadores sin escrúpulos. ${ }^{19}$

${ }^{18}$ Cf. p. 31, donde se subraya que la actividad literaria de la mayoría de los discípulos directos de Sócrates debió haberse concentrado sobre todo en los primeros treinta años del siglo IV. En el segundo cuarto de siglo, cuando la producción de diálogos disminuyó sensiblemente, cambió en buena medida el carácter general del diálogo.

${ }^{19}$ La defensa se manifestó también en el estilo de la oratoria epidíctica, es decir, en discursos logográficos ficticios, que diversos autores escribieron en defensa y en contra de Sócrates. En el primer caso se tiene la célebre Apología de Platón, quien de ese modo se inscribe también entre los logógrafos y entre los oradores áticos del siglo IV, y las de Jenofonte y de Lisias, éste último amigo de Sócrates, según Rossetti (p. 238). En el segundo, se menciona la Acusación contra Sócrates, de Polícrates, discípulo de Gorgias y denominado "el sofista" (DL 2.38), cuyo discurso es considerado curiosamente - desde mi punto de vista - un "panfleto" por los estudiosos modernos (incluido Rossetti), 
3. Aspectos cuantitativos. En cuanto al número de diálogos publicados, el autor subraya en su primer ensayo que, durante el primer cuarto del siglo IV, se verificó una verdadera avalancha de diálogos que imitaban de una manera más o menos auténtica o ficticia el arte dialógico del maestro: Jenofonte (en sus Memorables), Esquines de Esfeto, Fedón y Euclides publicaron numerosos diálogos, además de otros socráticos menores. La producción de Platón es abundante en esos años, antes de elaborar su edificio doctrinal transmitido también en forma dialógica. A ese primer periodo pertenecen los diálogos aporéticos, entre los que se cuenta el Eutifrón (cf. p. 125), estudiado por nuestro autor en este volumen (Cap. 4).

Rossetti llega a la conclusión de que los discípulos directos de Sócrates publicaron aproximadamente doscientos diálogos (p. 29) y que las unidades dialógicas (es decir, diálogos encuadrados en una narración) alcanzaron el número de trescientas, si no es que más (p. 31). Se puede conjeturar que durante los primeros 25 años del siglo IV a. C. se publicó de manera proporcional un diálogo por mes: "Atenas presenció una verdadera inundación de logoi sokratikoi, inundación para la cual no conocemos ningún término de comparación ni en nuestra época ni en ninguna otra" (p. 32). Sin tomar en cuenta los diálogos anónimos cuyos rastros pueden encontrarse aquí y allá en los textos antiguos (cf. pp. 35-38), se trata - como bien lo señala el estudioso perusino- de cifras enormes, fenómeno que no ha llamado particularmente la atención de los estudiosos.

Lo anterior plantea la necesidad de estudiar los factores que favorecieron el nacimiento de un verdadero género literario y filosófico que predominó durante las primeras décadas del siglo IV; analizar su desarrollo y sus características, ${ }^{20}$ y revalorar el impacto que este fenómeno

aunque se trata de un texto epidíctico, de cuyo valor no podemos opinar, pues no se conserva.

${ }^{20}$ Un asunto que Rossetti trata de manera marginal es la clasificación de los diálogos socráticos en su conjunto. La lectura del libro me sugiere una clasificación basada en el criterio de la causa eficiente, es decir, por el autor. Así, pueden individuarse diálogos de discípulos inmediatos (cf. p. 31 et passim, que a su vez se dividen en fundadores de escuelas y autores menores), de discípulos mediatos, de autores anónimos (cf. p. 33) y diálogos espurios o falsos. No es una clasificación gratuita, pues presumiblemente cada autor da al texto su toque personal. Es complicado establecer otros tipos de clasificaciones (por ejemplo, una basada en el criterio de causa final) debido a la pérdida de la mayor parte de los diálogos socráticos. En cambio, sí se han pro- 
tuvo en el medio intelectual de la época: la destrucción del prestigio de los sofistas y de otras escuela filosófica de la época, y la consecuente imposición de las escuelas socráticas como la filosofía predominante. En sus ensayos Livio Rossetti presenta los principales problemas y ofrece explicaciones a cuestiones medulares.

La presentación de los datos y su interpretación por parte de L. Rossetti requiere de tres comentarios. El primero es sobre la producción filosófica dentro de los grupos socráticos. Se observa en el libro que los discípulos no se limitaban a escribir diálogos, sino que fueron más allá, pues también abordaron la historia, la epistolografía, el tratado y otros géneros, algunos de los cuales no trataban sobre el maestro, como sucedió, por ejemplo, con Aristipo (pp. 27-28) o Jenofonte. Sin embargo, Rossetti parece incluir entre los diálogos obras que no pertenecen a ese género, como algunas obras de Antístenes (cf. p. 26), la Apología de Platón e inclusive la Apología de Lisias (p. 28).

El segundo comentario tiene que ver sobre la actividad literaria global. Se deben justipreciar las cifras proporcionadas en relación con el número de diálogos socráticos en el contexto de la producción escrita en la primera mitad del siglo IV. Por ejemplo, si comparamos con el número de discursos producidos en la misma época, la proporción es por completo desfavorable a los diálogos. Pongamos el caso de Lisias - contra quien Platón escribió su Fedro-, a quien se atribuían en la antigüedad 425 discursos (entre auténticos y espurios), lo que superaría en mucho el número del total de diálogos. Así, en su conjunto, el número de discursos escritos era enorme, e inimaginable el número de discursos pronunciados.

El tercer comentario es cualitativo. Los discursos indicados no sólo tenían un alto valor artístico y cultural sino que también ejercieron una enorme influencia política y educativa. De lo anterior puede dar una idea la opinión de H.-I. Marrou, quien hace una comparación entre Isócrates y Platón, y concluye que, en términos generales,

fue Isócrates y no Platón el educador de la Grecia del siglo IV y, después de ella, del mundo helenístico primero, y romano más tarde [... ] es a Isócrates, mucho más que a cualquier otro, a quien le cabe el honor y la responsabili-

puesto clasificaciones de los diálogos de Platón como veremos más abajo (cf. infra, p. 263). 
dad de haber inspirado la educación predominantemente literaria de nuestra tradición occidental (1970: 96).

M. I. Finley también se refiere a esa "total victoria de la retórica" y explica cuáles fueron sus causas (Finley 1984, pp. 304-306). De esta manera, el discurso (macrología) y el diálogo (micrología) se encuentra en una especie de competencia cultural con la victoria del primero sobre el segundo.

4. Entre realidad discursiva y ficción literaria. Los discípulos desplegaron el elogio del maestro sobre todo en forma dramatizada. Uno de los problemas centrales de la "cuestión socrática" es definir hasta qué punto el diálogo socrático reproduce acontecimientos realmente sucedidos. En principio se puede estar de acuerdo de que en un diálogo se mezclan elementos que respetan la fidelidad histórica y la libre reelaboración (pp. 130-132). L. Rossetti distingue lo que se presta a la manipulación y lo que no. En el primer caso se pueden incluir las doctrinas atribuidas a Sócrates y el desarrollo preciso de algún encuentro; en el segundo, como ya se ha dicho antes (p. 246), las analogías triviales, los contra-ejemplos, la creación de una atmósfera, discursos breves, y sobre todo la dramatización de una situación en la que se muestra a un interlocutor que poco a poco se ve en dificultades, entre otros aspectos característicos del dialogar socrático (pp. 133-134). Se trata, por tanto, de diálogos cuyos planteamientos doctrinales y estructura no son atribuibles al personaje principal, sino al autor. Sin embargo, lo anterior no quiere decir que el diálogo no hubiera tenido lugar.

El problema central de la "cuestión socrática" es descubrir quién es el verdadero Sócrates: el de Aristófanes, el de Platón, el de Jenofonte o una mezcla de los tres. Los historiadores de la filosofía han llegado a la conclusión de que es imposible saber quién fue el Sócrates histórico. La discusión al respecto había caído en un impasse. Roustang subraya (p. 19) que, en este contexto de confusión, Rossetti presenta una solución definitiva al enigma socrático: el Sócrates de carne y hueso es la persona histórica que él delinea a partir de la distinción de los elementos propios y ajenos presentes en los diálogos. Es aquel hombre dedicado a enseñar a un grupo de discípulos un modo singular de debatir para refutar con éxito a quienes se vanagloriaban de poseer la sabiduría. 
Sin duda se trata de una contribución significativa a uno de los debates más conocidos de la filosofía antigua. Sin embargo, Rossetti no se expresa con claridad sobre un punto vinculado con el anterior: ¿los diálogos son reales o son invenciones de los filosofos? Lo que llega a decir es que, en parte, son una invención y, en parte, reproducen un estilo socrático de dialogar, pero no se decide a afirmar o negar que los diálogos hubieran tenido efectivamente lugar, aunque más bien parece tender a lo último. ${ }^{21}$

\section{El instrumento de análisis: la macro-retórica}

1. La doctrina macro-retórica. En su afán por resolver el enigma de la inveterada quaestio socratica, el estudioso perusino se vio en la necesidad de elaborar un método de interpretación apropiado a su objeto de estudio: la "macro-retórica", cuyos procedimientos, sumamente eficaces en la creación de una comunicación de calidad, no han sido considerados en la retórica estándar, que él denomina como "micro-retórica. Por lo anterior, Rossetti reformula el concepto de 'retórica' como la disciplina "que se ocupa sólo de aquello que es decisivo para el éxito de la comunicación" (p. 221). Subraya que la comunicación eficaz difícilmente se logra mediante los procesos textuales codificados por la tradición. Asimismo, su aplicación al estudio del discurso sólo permite observar la superficie del texto, aquello que está expreso, pero no lo que se encuentra escondido detrás de las palabras y que escapa con facilidad al escrutinio del estudioso. En cambio, los expedientes macro-retóricos son instrumentos eficaces tanto para la elaboración discursiva de calidad como para el descubrimiento y descripción de la eficacia comunicativa.

${ }^{21}$ En Rossetti 2004 se observa que el Sócrates que tenemos es de segunda mano, es la representación que intentaron elaborar los escritores de diálogos. "Esos logoi son claramente ficticios" (Rossetti 2004, p. 81). Sin embargo, observa que los diálogos socráticos contienen tanto elementos ficticios que no corresponden al verdadero Sócrates, como elementos comunes en los diálogos que muestran al Sócrates real, quien "hace cosas con palabras y afecta no sólo las opiniones, sino también las costumbres de sus interlocutores [...]" (p. 93). De tal modo, considera que es posible encontrar y estudiar las áreas transparentes que nos pueden llevar al verdadero Sócrates sólo después de haber analizado todos los diálogos en su conjunto y de eliminar los elementos oscuros que muestran a un Sócrates deformado y ficticio. 
¿Cómo descubrir, describir y sistematizar esos expedientes? Lo anterior se logra mediante una especie de desdoblamiento del modelo empleado por el propio Sócrates en su práctica dialógica y la observación atenta de ciertos elementos discursivos metatextuales empleados con maestría en la planeación de la estrategia comunicativa. Así, la "facultad de adaptación" juega un papel de primer orden en la calidad y eficacia de la comunicación; tiene que ver ante todo con la forma de organizar el intercambio dialógico a fin de vencer las resistencias del interlocutor o de los oyentes-lectores, y producir en ellos compromiso, sugestión o persuasión (p. 220).

Esta notable concepción retórica plantea tres cambios fundamentales frente a la tradición: (a) ampliar el campo de la retórica, (b) definir los fines y $(c)$ aplicar los medios macro-retóricos adecuados a los fines. Con base en los puntos $b$ y $c$, Rossetti reconstruye un "modelo dialógico" (p. 216), "modelo conscientemente alternativo" y personal de Sócrates basado en mecanismos "macro-retóricos" relativos a la "planeación estratégica".

En cuanto al primer punto, Rossetti observa:

Se está muy de acuerdo en referirse a la forma socrática de organizar la interacción comunicativa, de llevar un intercambio verbal, de hacer que los interlocutores duden de sus convicciones y principios que rigen sus vidas, pero no se considera todo ello como retórica (p. 217),

y termina preguntando: “¿Entonces, se puede negar que una comunicación dirigida a condicionar la psychê de los destinatarios a los cuales ella misma se dirige tiene que ver con la retórica?", y poco después: “¿Por qué rehusarse a ver estrategias retóricas en las estrategias dialógicas? ¿Por qué esta repugnancia a llamarlas 'retóricas'?” (p. 219). La explicación o parte de ella es simple: "estamos aún bajo los efectos de la retórica de la anti-retórica socrático-platónica, casi incapaces de escapar a sus condicionamientos y de interesarnos en un retrato no ideológico de la filosofía" (p. 224). ${ }^{22}$

${ }^{22}$ A mi modo de ver, la noción peyorativa de la retórica proviene de una lectura parcial de la posición de Platón frente a ese arte. El filósofo se oponía a la retórica de las escuelas que competían con la suya, pero presenta la propia, aquella retórica holísti-

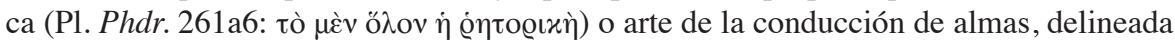
en la segunda parte del Fedro, que consiste en adquirir la capacidad de hablar y escribir 
Frente a lo anterior, en el libro se emplea el término retórica más allá de los estrechos límites que le impusieron Aristóteles - quien la circunscribió a los tres géneros canónicos - y en general la tradición griega y romana, y extiende el campo de la técnica macro-retórica a los problemas de la filosofía y en particular al diálogo. Afirma con seguridad: "No es sólo el político y el empresario, el comerciante y el anunciante, el comediante y el pastor, el médico y el agente de ventas que llegan, cada uno a su modo, a imponer sus ideas, a persuadir, engañar o fascinar. También el filósofo" (p. 225). Y entre todos — diría yo- uno de los más destacados en el arte de la eficacia comunicativa (léase también: en el arte de engatusar a sus oyentes) fue precisamente Sócrates, "gran maestro de la manipulación de las emociones" (p. 222), a quien, por lo tanto, puede adjudicársele una retórica propia.

Quisiera agregar algún comentario en relación con la "micro-retórica". Nuestro autor se refiere en específico al libro cuarto de la Retórica a Herenio (dedicado a las figuras), a Pierre Fontanier (1960, quien escribió dos obras fundamentales sobre las figuras en 1821 y 1827) y a Henrich Lausberg (1960), cuyo Manual puede considerarse como la Biblia de los estudios literarios, además de referirse a "numerosos tratados posteriores", pensando en especial, tal vez, en la Retórica General del Grupo $\mu$ (1969). En ellos: "La regla ha sido sobre todo considerar sólo una parte no esencial de estos procedimientos como el verdadero objeto de la ciencia retórica: los procedimientos micro-retóricos codificados" ( $p$. 220). Es evidente que tales obras abordan sobre todo los elementos del ornato, parte mínima de la retórica que pasó a considerarse como el arte de la palabra en su totalidad. Pero el estudioso no toma en consideración los libros I-III de la misma Retórica a Herenio, la Retórica de Aristóteles, la Retórica a Alejandro, las Instituciones oratorias de Quintiliano, y muchas otras más tanto antiguas como modernas, porque piensa, tal vez, que no integran ni influyen en la corriente predominante de la retórica en época moderna y en la actualidad. Sería oportuno valorar tales obras.

En cuanto al segundo cambio fundamental, en el estudio de la retórica se debe identificar la finalidad del orador. Rossetti observa (pp. 245-246) que existen dos "lados" de la comunicación: uno es el enunciativo, que

bien tanto en asuntos políticos como privados, tanto en problemas importantes como insignificantes, tanto en prosa como en verso (P1. Phdr. 257b9-258e5 y 261a6-b2), una disciplina que se base en la unión y en la división (Pl. Phdr. 266b), que ponga atención en el orden (Pl. Phdr. 266d) y cuide del estilo (Pl. Phdr. 277b), entre otras cosas. 
busca dar un sentido a los enunciados y a las estructuras; otro, el paraenunciativo, que se dirige a dar sentido a experiencias como las emociones y las sugestiones. Este último constituye la "zona oscura de la comunicación", la parte retórica, o más propiamente dicho, la macro-retórica. Señala en principio que no existe una finalidad única sino una variedad de fines jerarquizados. La finalidad enunciativa consiste en transmitir un saber o un conocimiento, que es, sin embargo, una voluntad extrínseca al esfuerzo comunicativo retórico (p. 226). Este último consiste en producir un cierto efecto, y para lograrlo, se busca engendrar una emoción dada (asombro, curiosidad, confianza, inquietud...), preparar el terreno para lanzar lo que se considera esencial, destacarlo y comunicarlo gracias a esa preparación (p. 226). Nuestro autor identifica una serie de efectos retóricos socráticos (pp. 227-231) que constituyen e identifican el proyecto macro-retórico. Su crítica del "famoso Tratado" de Chaïm Perelman y Olbrechts Tyteca (1958) se debe precisamente a que "pasa casi enteramente en silencio los objetivos perseguidos por el locutor, sobrevolando así los fines y la adecuación de los medios a los fines, y por tanto el proyecto macro-retórico que rige la elección de los detalles singulares" (p. 59).

Por último, Rossetti identifica novedosos y variados mecanismos -en general no considerados o poco importantes en la retórica tradicionalque permiten a Sócrates (y también al discípulo o a su seguidor) alcanzar el efecto deseado y, así, derrotar o someter a un interlocutor generalmente presentado como arrogante y presuntuoso. Entre los mecanismos más destacados se encuentran: el flujo comunicativo u organización del intercambio, la instauración de una atmósfera apropiada, el formateo y la saturación comunicativa (pp. 220 y 232-236).

Sobre lo anterior me permito hacer una acotación. En la p. 224, el autor se refiere al intento de Sócrates de "dar una imagen de sí mismo", mediante lo cual se busca "suscitar, provocar y desarrollar un sentimiento ante todo de admiración, subordinación, gratitud y confianza, una disposición a dejarse influenciar [...]" (p. 224). Considero que los elementos macro-retóricos como el anterior se encuentran integrados en la importante noción del êthos (o tropos) que - desde mi punto de vistaabarca tanto la honestidad y equidad del hablante como los comportamientos y actitudes propias de los oyentes y de terceras personas (en el caso del género epidíctico) y que consiste precisamente en la adaptación del emisor al contexto y al destinatario, con la mira puesta de antemano en cambiar la situación y el propio êthos del oyente. El êthos idealiza- 
do de Sócrates es el de una persona virtuosa frente al comportamiento "real" (provocativo, despectivo, elitista, p. 199) que pudo haber tenido frente a algún tipo de personas. A pesar de todo, es cierto que los estudios tradicionales de la retórica no han puesto atención en los elementos estudiados por nuestro autor, independientemente de que él considere que sus aportes pertenezcan o no al estudio del êthos.

2. Elementos macro-retóricos. La parte medular o el eje del arte socrático es el "flujo comunicativo", forma en que Sócrates y sus discípulos organizan la estructura del conjunto del diálogo. ${ }^{23}$ Consta de varias etapas. La primera consiste en despertar el interés del interlocutor en participar en la discusión sobre un asunto que cree dominar. Entre los numerosos expedientes se pueden mencionar las alabanzas que el interrogador dirige al interlocutor. La duración de esta etapa puede ser más o menos amplia. En el caso del Eutidemo de Jenofonte dura varios días; en otros pude ser breve, como en el caso del Eutifrón de Platón.

Después de ello, el interlocutor acepta responder brevemente a las preguntas y comienza una sesión en la que el interrogado intenta responder a las refutaciones que le va presentando el maestro. Se debe llamar la atención sobre la fundamentación, pertinencia y oportunidad de las respuestas dadas por el interlocutor y los contraejemplos puestos por Sócrates. En general, la actitud de éste ante las respuestas (pensemos en la definición del concepto de "valor") es radical: una definición debe valer siempre, pero al parecer invariablemente hay contraejemplos que muestran que ello no es así. El interlocutor aparece por lo regular demasiado condescendiente frente a Sócrates, pues en vez de discutir sobre la misma definición que él ha ofrecido, está de acuerdo en ofrecer otra, que será igualmente refutada con otros contraejemplos. ${ }^{24}$ Por tanto, no se trata de una secuencia episódica, sino que se procede "a saltos". Por otra parte, los contraejemplos resultan con frecuencia cuestionables, ya sea porque no son pertinentes o bien porque contienen los mismos defectos que se observan en la definición dada al principio. ${ }^{25}$ Los contraejemplos

${ }^{23}$ Cf. p. 218. Rossetti señala en diferentes pasajes el recorrido "por etapas" de un diálogo socrático estándar (cf. pp. 134-136, 200-201).

${ }^{24}$ Esta actitud es particularmente evidente en el caso del Cármides platónico.

${ }^{25}$ Cf. pp. 203 y 250-251 (donde se observa que Eutifrón ofrece una definición más adecuada que la del propio Sócrates). 
empleados por el maestro y sus discípulos son una trampa mortal para el interlocutor (y para el lector de hoy), un mecanismo de refutación incuestionable.

Como observa Rossetti, los contraejemplos socráticos presentan errores o les falta sustento. En el caso del Eutidemo, se refiere (p. 75) a la noción de "verdad complementaria", que se aplica cuando una situación o afirmación no excluye necesariamente la contraria, como si se dijera "la otra parte de la verdad" (expresión mía). Pone el ejemplo heracliteo: se puede decir que uno se mete en las mismas aguas del río, pero es cierto también que el agua se renueva de manera constante. Ambas afirmaciones son verdaderas (p. 75). Desde mi punto de vista, y en consonancia con lo anterior, esos contraejemplos podrían considerarse como excepciones que confirman la regla. Se quiere aplicar una definición a todos los casos en absoluto sobre problemas que pertenecen al campo de la opinión, de la doxa. Una ley, un precepto o una costumbre tienen un carácter general, pero deben adecuarse o acomodarse a los casos concretos o a situaciones especiales que no entran del todo dentro de la regla. A lo anterior se le denomina criterio de "equidad" (epieíkeia, aequitas, cf. Arist. Rh. 1374a-b). Su aplicación resulta muy útil sobre todo en los tribunales, y debería serlo también en la filosofía. Tal parece que Sócrates y los socráticos, incluido Platón, estuvieron faltos de ese sentido de equidad.

Luego de los intercambios y de caer en el juego de manera por demás ingenua, el interlocutor se declara tácitamente incapaz de dar una respuesta adecuada. En esta secuencia se encuentra una serie importante de expedientes comunicativos de gran valor para la retórica del diálogo socrático.

En el caso de los diálogos aporéticos (Platón), puedo identificar tres partes: principio, desarrollo o agôn y desenlace. El principio termina con la disposición del interlocutor de responder a las preguntas. El agôn presenta varios episodios que constituyen intentos por encontrar una definición apropiada y refutaciones mediante contraejemplos. Por último, en el desistimiento el mismo interlocutor renuncia a continuar. Por ejemplo, Eutifrón (Cap. 4), en el diálogo homónimo de Platón, al quedar aturdido por las preguntas de Sócrates y no poder continuar, cierra el diálogo con el pretexto trivial de que tiene cosas importantes que hacer. Sin embargo, no todos los diálogos parecen apegarse a este esquema, sobre todo en lo relativo a la parte del desarrollo. Por tanto, es necesario encontrar un 
"denominador común" que valga tanto para el Eutifrón como para las Leyes; para los diálogos aporéticos como para los expositivos; para los de Platón como para los de otros socráticos, lo cual no me parece que se haya hecho.

En este marco de la macro-retórica, Rossetti rescata "nociones complementarias como eirôneia, humor, elenkhos, agnoia, mayéutica, protrepein, mêtanoia, psykhagôgia, además de la inducción y la definición" (p. 216, cf. p. 222), que deben considerarse como procedimientos retóricos (p. 225). A éstos agrega el arte de la ridiculización, estrategia en la que se detiene ampliamente (pp. 195-212) con el fin de mostrar la maestría de la que hacían gala Sócrates y sus discípulos.

La ridiculización, a diferencia de lo cómico, ya sea inducida o espontánea, ${ }^{26}$ tiende a cumplir una función pragmática seria; sus efectos tienen un carácter casi irreversible y constituye un riesgo permanente para todos, pues está ligado a la "metida de pata". Sócrates (e igualmente Platón) utilizó esta arma poderosa para atacar a los sofistas con éxito, pues aún hoy produce efectos que, en términos generales, no han sido neutralizados por los lectores y estudiosos de los diálogos. ${ }^{27}$ Fueron muchas las víctimas de Sócrates, en general ciudadanos que se vanagloriaban de ser expertos (sophoi), y se veían enredados en una maraña de trampas argumentativas semejantes a las aporías de Zenón, incapaces de escapar de ella. En esa trampa se vio envuelto Ánito, ridiculizado en público

${ }^{26}$ En este caso es notoria la capacidad de L. Rossetti de orientar con claridad el estudio, discriminando los términos parecidos al del "ridículo", y llegar a distinguir el "ridículo inducido" en la que Sócrates se presenta como un autentico maestro.

${ }^{27}$ Rossetti se refiere a la ridiculización (utiliza la expresión "le ridicule") que distingue de lo cómico, como si se tratara de la famosa ironía socrática, pues afirma: "Abordemos ahora algunos elementos de la ironía socrática" (p. 199). Sin embargo, no se trata de la ironía socrática, sino de otro tipo de ironía. Asimismo, abundando sobre lo anterior, habrá que observar la diferencia entre "hacer el ridículo" y "ridiculizar", y que muchas veces se puede caer en el ridículo en privado, sin la existencia de un público. Un ejemplo de la diferencia indicada es el siguiente: un hombre maduro encuentra en el hospital a un conocido suyo con su mujer enferma, y le dice: "Oh, no tenía el gusto de conocer a tu mamá". El hombre no sabía dónde meter la cara cuando el conocido le aclaró que no era su mamá sino su esposa. Podría haber sucedido también que el mismo hombre hubiera dicho lo que dijo con toda la intención de ridiculizar a su conocido. Rossetti se refiere a una ridiculización diferente, aquella que es disimulada, planeada, dosificada y que concluye con la asunción por parte del interlocutor de no poder salir del atolladero al que Sócrates lo ha conducido. 
como un ignorante engreído. A la postre, descargó su ira contra Sócrates en el proceso del $399 .{ }^{28}$

3. Ejemplos. Rossetti tiene la sana costumbre de recurrir de modo regular a la ejemplificación en apoyo de sus afirmaciones, de manera que a lo largo del libro analiza numerosos pasajes y diálogos completos. Para mostrar con mayor claridad las características de la técnica dialógica, presenta una comparación general entre Sócrates y Gorgias (Cap. 6, pp. 236-243) que pone de manifiesto las grandes diferencias existentes entre un autor de diálogos y un autor de discursos en el empleo de las estrategias macro-retóricas. Ambos tipos de proyectos (discurso y diálogo) poseen fines semejantes, pero emplean estrategias diferentes. Por ejemplo, aunque ambos quieren ganarse la confianza de sus destinatarios, Gorgias recurre a la claridad, señalando lo que va a decir y a dónde quiere llegar, mientras que Sócrates esconde sus propósitos y no indica el camino que luego resulta tortuoso y complicado. También ambos recurren a la rapidez, pero Gorgias lo hace siguiendo una linealidad casi geométrica, mientras que Sócrates recurre a ella sólo en determinados momentos y en otros detiene la marcha. Asimismo, pueden notarse diferencias entre ambos maestros en relación con otras estrategias discursivas como el formateo, la saturación o la imagen que cada quien ofrece de sí mismo. La comparación resulta muy didáctica para entender los procedimientos macro-retóricos, que no son exclusivos de Sócrates ni de su escuela, sino un patrimonio comunicativo al que todo hablante tiene acceso. El filósofo ateniense logró sistematizar y enseñar a sus discípulos esas técnicas, como se muestra en seguida.

Veamos dos ejemplos de Jenofonte que ilustran lo anterior. Uno de ellos es el pasaje del capítulo IV 2 de los Memorabilia de Jenofonte, el cual podría ser el resumen de un diálogo auténtico mucho más amplio y detallado, transmitido de manera oral o escrita, reproducido por el discípulo en la forma semi-dialógica característica de sus Memorabilia, y denominado por el propio Rossetti como el Eutidemo. Se trata de un diálogo clave para entender el arte retórico de Sócrates, pues en él se ponen al descubierto los objetivos y las estrategias comunicativas empleadas, que nuestro autor analiza detenidamente en un largo capítulo (Cap. 2, pp. 55-99).

${ }^{28}$ Como veremos más abajo, el Eutidemo de Jenofonte y el Eutifrón de Platón son otros dos casos de ridiculización ejemplares. 
Eutidemo es un adolescente serio que tiene la pretensión de convertirse en un gran dirigente de la democracia, para lo cual había recibido una óptima educación. Estaba seguro de superar a los demás de su edad en el arte político gracias a su amplio conocimiento de obras de poetas y maestros reconocidos en ese arte. ${ }^{29}$ Sócrates tiene referencias de ese joven, y decide abordarlo y someterlo. Para ello pone en juego las estrategias macro-retóricas que antes se han esbozado: primero (pp. 59-67) prepara la ambientación y realiza el formateo, mediante elogios y otros subterfugios que sirven para atraer a la presa y ponerla a su entera disposición, sin la menor resistencias. Luego lo hace caer en la trampa que le ha tendido en una serie de tres episodios o series de cuestionamientos mediante ejemplos (pp. 67-89), separados por una tregua antiepisódica después de la primera serie (pp. 76-81). Sócrates conduce al joven, demasiado complaciente ya, a seguir el recorrido que él mismo le va indicando. La primera serie trata sobre las definiciones de lo justo y lo injusto. Eutidemo ofrece ejemplos de lo injusto, y Sócrates lo refuta mediante contraejemplos que, sin embargo, son de casos límite, realmente excepciones a la regla, que el joven es incapaz de neutralizar. Luego del descontrol sufrido por el interlocutor, sigue una pausa, que le permite a éste "tomar aire". Sigue el segundo episodio de cuestionamientos, ahora sobre los bienes y los males, a los que Eutidemo responde con ejemplo de bienes, como la sabiduría y, al final, la felicidad, pero nada satisface a Sócrates, que para todo encuentra ejemplos que refutan de manera contundente lo dicho por el pobre muchacho. La tercera serie aborda el concepto de "democracia"; Sócrates instiga al muchacho a decir qué es el demos, y refuta sus buenas respuestas, sin que aquél encuentre la forma de oponerse a las insidiosas preguntas. Al término de esa serie constante de contraejemplos fulminantes, Sócrates deja que Eutidemo se retire completamente "desmoralizado, sin prodigarle ni una palabra de consuelo o de comprensión, como si él no hubiera sido el artesano intencional del desaliento que abruma a su interlocutor" (p. 89). Ya después Eutidemo habrá de regresar a los brazos de Sócrates, completamente domesticado, buscando la paideia del admirado maestro, lo cual justificaría el tormento mental aplicado por Sócrates al joven discípulo de los

${ }^{29}$ Se trata de los maestros de política llamados despectivamente sofistas por Platón. El maltrato dado por Sócrates al joven puede deberse a que era alumno de alguna de las escuelas contrarias, tal vez la de Gorgias o la de algún otro maestro famoso. 
sofistas (p. 90). En este caso no se trata de una ridiculización pública, sino interpersonal, pero igualmente desastrosa en el amor propio. Puedo agregar también que los contraejemplos utilizados por Sócrates no prueban necesariamente la inconsistencia de la definiciones aportadas por el joven interlocutor.

Así como Rossetti ha denominado un pasaje de las Memorabilia de Jenofonte como el Eutidemo, también es lícito denominar el Aristipo al capítulo 8 del libro III de esa misma obra, "diálogo" al que ya me he referido brevemente (cf. pp. 247-248, e infra, pp. 239 ss.). El intento infructuoso de Aristipo de aplicar las estrategias macro-retóricas contra su propio maestro parece probar que este mismo preparaba a sus discípulos en el arte de la disputa, quienes, además, buscaban las oportunidades de aplicar sus conocimientos prácticos y mostrar, tal vez al propio maestro, los avances obtenidos. En el Aristipo se muestra una vez más la aplicación de las reglas estándares encontradas en otros diálogos, con la gran diferencia de que la lógica del discurso aparece invertida, pues cambian los papeles desempeñados por el maestro y el discípulo: ahora es éste quien funge como interrogador asumiendo la posición de Sócrates, quien, sin embargo, no responde de la manera esperada, rompiendo así las propias reglas del juego. De cualquier modo, el ejercicio, aceptado por el propio maestro, muestra que Aristipo, a pesar del fracaso, se desenvuelve con cierta maestría, como puede colegirse del breve intercambio de palabras registradas por Jenofonte. ${ }^{30}$

Además del "flujo comunicativo", los expedientes macro-retóricos fundamentales son: ambientación, formateo y saturación. La primera consiste en que el autor de la obra (o Sócrates en el caso de la conversación real) instaura una atmósfera adecuada para la emisión-recepción del texto; el segundo, en que crea una forma mentis que condiciona al lector (o interlocutor) y su modo de entender lo que está leyendo (o escuchando), y, por último, en que el mismo autor hace entender a sus lectores/

${ }^{30}$ Rossetti observa la extraña introducción de "el excursus de orden urbanístico" que aparece en los últimos parágrafos de este breve capítulo (III, 8, 8-10). Puede tratarse de un pasaje de otro diálogo que Sócrates pudo haber sostenido con alguien [se podría tal vez pensar en un sophós en el arte de Hipódamo] sobre cuestiones urbanísticas y que se integró aquí por una simple "asociación de ideas". Se podría pensar también que se trata de un pausa o tregua, a la que podía seguir otra u otras series de preguntas y respuestas, pues, en efecto, el diálogo entre Sócrates y Aristipo no parece tener un final, al igual que sucede en otros casos. 
oyentes lo que debería ser considerado satisfactorio (pp. 233-235). En la Apología, Platón crea las condiciones necesarias para lograr que sus lectores concluyan su lectura con una gran empatía y admiración por Sócrates, quien muestra su enorme pericia en el manejo de esos mecanismos de primer orden. ${ }^{31}$

\section{Los diálogos de Platón}

1. Los diálogos aporéticos. Los problemas planteados en las páginas anteriores se manifiestan con claridad en los diálogos de Platón. En el conjunto de la actividad dialógica, la primera dificultad es de carácter tipológico, a causa de la pérdida de la mayor parte de esa literatura. ${ }^{32} \mathrm{Sin}$ embargo, en el caso de los diálogos platónicos sí es posible establecer una tipología, a lo cual, empero, no se le ha dado la importancia que merece. ${ }^{33}$ L. Rossetti clasifica los diálogos en aporéticos o zêtêtikói (que no logran establecer una definición) ${ }^{34}$ y en expositivos o hyphêgêtikói (esto es, que producen una enseñanza mediante una exposición). El estudioso perusino observa que la diferencia básica entre el diálogo aporético y el hyphêgêtikós es que el primero presenta la investigación en

${ }^{31}$ No voy a abundar aquí sobre estos puntos, para los cuales véase el texto publicado en 1994 y traducido al español en 2009: Estrategias macro-retóricas, donde Livio Rossetti presenta un estudio amplio sobre esos mecanismo de manipulación.

${ }^{32}$ Cf. supra, p. 250, n. 20.

${ }^{33}$ Cf. Rossetti 1996, p. 330, refiriéndose en especial a Vlastos 1988.

${ }^{34}$ Los críticos antiguos y modernos han elaborado diversas clasificaciones de los diálogos platónicos (pero no de los diálogos en general). En la antigüedad Trásilo los habría dividido en nueve tetralogías; Jámblico habría establecido un orden de estudio (ética, lógica, física y teología); Diógenes Laercio (III.49-50), basándose en Trásilo, reprodujo una clasificación que divide el diálogo socrático en dos tipos principales

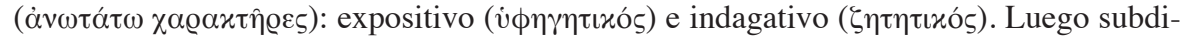
vide el primero en teórico y práctico ( $\theta \varepsilon \omega \varrho \eta \mu \alpha \tau \iota x o ́ s, ~ \pi \varrho \alpha x \tau \iota x o ́ \varsigma)$; en seguida, el teórico

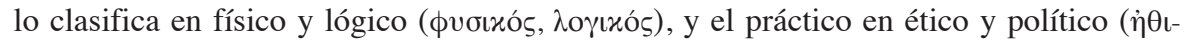

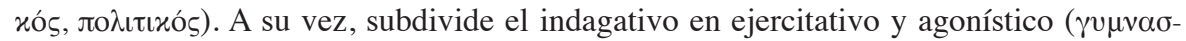

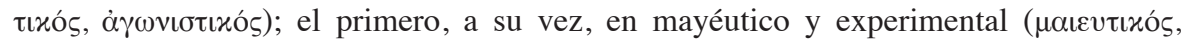

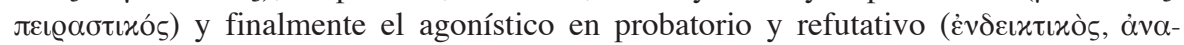

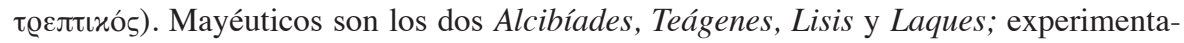
les: Eutifrón, Menón, Ión, Cármides y Teeteto; hay un sólo probatorio, el Protágoras, mientras que refutativos son: Eutidemo, Gorgias y los dos Hipias. En nuestra época se tiende a utilizar un criterio cronológico: diálogos de juventud, de la madurez, de la vejez (p. 251); antes o después del primer viaje, etcétera. 
curso, sin llegar a conclusiones, produciendo en el receptor una serie de emociones contrastantes frente a los interlocutores que participan en el diálogo y ejerciendo una influencia profunda en la forma de asimilar el debate (p. 141-143). Esta "investigación en curso" tiene una importancia particular, pues en ello radica la propia definición de filosofía como un movimiento a la sophía, no como la posesión de ella (p. 276, cf. infra, p. 270).

Sin embargo, más allá de estas diferencias extratextuales, nuestro autor muestra cómo ambos géneros siguen patrones de organización diferentes. En términos generales, según puedo colegir de la obra en comento, en los diálogos aporéticos Sócrates aparece, salvo casos aislados, en su calidad de interrogador, haciendo objeciones y presentando contra-ejemplos a un interlocutor que en general se doblega a las "reglas del juego" impuestas por él, a pesar de sus vanos intentos por salir airoso del debate; en los hyphêgêtikói, en cambio, el personaje principal, generalmente Sócrates, presenta una actitud académica, de maestro de escuela, mientras que el interlocutor aparece condescendiente con la exposición del personaje principal, limitándose a reafirmar las enseñanzas del maestro, en una atmósfera serena, sin sobresaltos. En este caso, Platón se dirige esencialmente a los colegas (1996, p. 335) o a intelectuales proclives al maestro.

Empero, la aportación de Rossetti se muestra, de manera particular, en la identificación de elementos macro-retóricos que distinguen los diálogos aporéticos de los expositivos. La diferencia se encuentra en la secuencia u organización de los diálogos, en la desigualdad de las relaciones entre ambos personajes dramáticos y en la utilización de diferentes estrategias comunicativas.

En el caso de los diálogos hyphêgêtikói, ${ }^{35}$ que transmiten una doctrina, la secuencia es muy diferente: $(a)$ el locutor principal dispone de antemano de un saber y está preparado para hacer una exposición al respecto; $(b)$ el interlocutor, competente y relativamente agudo, se preocupa

35 Una exposición amplia se encuentra en Rossetti 1996, pp. 330-341. En la p. 319 dice: "si Platón hubiese escrito un tratado en vez de un diálogo [...]", afirmación que me lleva a pensar en una sugerente transición (aunque no necesariamente real) entre el teatro ateniense del siglo v, el diálogo aporético, el hyphêgêtikós y el tratado. En efecto, habrá de recordarse que Platón probablemente había escrito tragedias en su juventud, de modo que sólo le faltó transitar precisamente al tratado, el cual algunos de sus ex condiscípulos sí lo desarrollaron, como es el caso de Jenofonte, Aristipo o Antístenes. 
por entender bien las reflexiones y razonamientos del maestro, pero no osa hacer objeciones, en la idea de que éstas serían prematuras y de que podrían hacerse sólo después de haber reflexionado; (c) el diálogo se convierte en la parte central de una reflexión que comienza antes y prosigue después de la conversación.

Además, la relación entre el interrogador y el interlocutor presenta un evidente desequilibrio, tanto por la calidad intelectual de ambos como por la cantidad y peso de las intervenciones del interlocutor, quien a menudo se limita a seguir paso a paso al expositor "a fin de comprender, sin permiso de juzgar el valor [de lo dicho], sin el tiempo para reflexionar, evaluar, confrontar o volver a determinados pasajes" (p. 254). Sin embargo, las respuestas, aunque están limitadas por el nuevo formato, cumplen una serie de funciones importantes, como son confirmar o sancionar lo dicho por el personaje principal, organizar el flujo comunicativo, llamar la atención sobre la solidez o fragilidad de los argumentos, dar seguridad al lector sobre la alta plausibilidad de los razonamientos del personaje principal. ${ }^{36}$ De esta manera coadyuvan a la importante finalidad de "dar razón" por parte de los lectores al propio autor, esto es, a Platón mismo.

Le Dialogue socratique se aboca sobre todo al estudio de los diálogos aporéticos de Platón, los cuales se distinguen de los demás por cumplir una función particular: la búsqueda de una buena definición, la "investigación definicional" (p. 137), ${ }^{37}$ y por constituir una forma mixta entre la dimensión patética y la cómica, entre lo serio y lo jocoso, dimensiones que se encuentran fundidas en el diálogo (pp. 151-157). Tales características ha provocado malentendidos entre los estudiosos quienes optan ya por privilegiar una forma de comunicación u otra como elemento propio del diálogo, el cual busca no sólo divertir sino también incitar al lector a interrogarse sobre los problemas planteados. Rossetti describe un "secreto" adicional de estas obras, que él denomina "movimiento perpetuo" o "recorrido hiperbólico" y que consiste en la serie de intentos infruc-

${ }^{36}$ En las pp. 252-255, Rossetti muestra con cierto detalle la "función demostrativa ilegítima" (p. 255) de las numerosas fórmulas utilizadas por el interlocutor en ese tipo de diálogo platónico. Esa función consiste en darse a sí mismo la razón.

${ }^{37}$ El autor considera que sólo los diálogos platónicos de carácter aporético cumplen una función definicional, pero no los expositivos, cuyo propósito es transmitir un conocimiento ya adquirido en buena medida. Los diálogos no platónicos tampoco cumplen, según parece, esa función. 
tuosos por encontrar la definición válida de un determinado concepto, cuya virtud es lograr inmiscuir al lector en la búsqueda de ese ejercicio intelectual que no llega a concretarse (pp. 157-162).

Se debe subrayar que el libro no tiene el propósito de estudiar las ideas expuestas en los diálogos aporéticos o su contenido doctrinal, sino describir el proceso comunicativo, descubrir los expedientes macro-retóricos a los que ya me he referido y, en particular, las "reglas del juego" firmemente establecidas. Dichas reglas guían la discusión sólo entre Sócrates, quien funge como protagonista en su función de interrogador y gestor del debate, y los interlocutores, quienes se encuentran en un plano de inferioridad y a merced del protagonista. También el lector es objeto de una serie de efectos convenientemente encauzados mediante estrategias comunicativas de primer orden (pp. 144-148), que lo hacen identificarse y tomar partido por el protagonista. El lector es llevado a involucrarse de manera imperceptible en el debate, como si formara parte del público que presencia el intercambio discursivo.

Por último, el autor ofrece una respuesta a la "cuestión capital” acerca de los fines que impulsaron a Platón a componer estos diálogos en suspenso. Rechaza las dos respuestas más conocidas:

(a) Platón muestra simplemente su honestidad intelectual al admitir su incapacidad, por lo menos momentánea, de lograr encontrar la respuesta definitiva a los problemas planteados. Rossetti observa que ésta es una percepción mitificada acerca de los diálogos aporéticos: Platón concluye el diálogo donde él quiere y cuando él quiere, no porque reproduzca la incapacidad de su maestro de ir más lejos, sino porque él así lo ha decidido (pp. 163-164).

(b) El filósofo no ha querido mostrar o hacer públicas sus propias definiciones, sino que se ha contentado con ofrecer a sus lectores aquello que él considera una iniciación a la filosofía, pero no pone al descubierto su conocimiento al respecto. La refutación de tal idea por parte del estudioso italiano es contundente: a veces Platón pone en boca de Sócrates definiciones que resultan claramente limitadas y vulnerables como las de sus interlocutores. En realidad, el filósofo no tiene una cultura definicional radicalmente más evolucionada que la que enseña en sus diálogos, y muestra sólo lo que tiene (pp. 164-166). Por mi parte agregaría que, tal vez, debería creerse en la afirmación de Sócrates de que lo único que sabía es que no sabía nada: o Sócrates miente al repetir esa declaración para tomarle el pelo a sus interlocutores y a sus lectores, o dice la verdad 
sobre su ignorancia en torno a los problemas de definición. Si se piensa que era sincero, deberíamos de aceptar la segunda posibilidad.

Rossetti opta por una tercera posibilidad: "Platón se contenta con fijar una metodología y no pretende llegar de inmediato a resultados definitivos" (p. 166); ofrece una técnica definicional novedosa que permitiría a sus lectores llevar a cabo reflexiones bastante complejas.

En consecuencia, la función del diálogo aporético es mostrar cómo se puede refutar, pero la finalidad es diferente: la alabanza de Sócrates y el vituperio de los adversarios son una forma de hacer propaganda de la propia escuela (por lo menos en el caso de Platón) y de la formación cultural e ideológica que en ella se imparte.

A lo anterior me permito agregar tres observaciones. (a) La metodología no parece llevar a resultados satisfactorios, sino a veces sólo a encaminar en el análisis de problemas de definición de carácter éticopolítico, sobre todo para encontrar las deficiencias en las concepciones expuestas. (b) Como consecuencia de ello, es probable que la técnica definicional no enseñe los medios que permitan alcanzar definiciones satisfactorias sino, más bien, las estrategias para refutar definiciones supuestamente erróneas. Tal parece que cualquier definición puede ser objeto de refutación mediante ejemplos. (c) Asimismo, no se trataría de la exposición de una técnica o de un método, sino de la ilustración de ese arte de refutación definicional mediante ejemplos dialógicos.

Asimismo, me atrevo a sugerir que el arte del diálogo aporético se encuentra en los Tópicos de Aristóteles, en particular en el libro sexto donde se aborda las formas adecuadas para definir y los "lugares" que se pueden emplear al respecto. Un ejemplo de lo anterior es el siguiente: para definir una expresión es necesario emplear palabras claras; evitar, entre otras expresiones, los homónimos, las metáforas o los términos inusuales, con el propósito de impedir que el adversario ataque; en cambio, el examinador puede atacar al interlocutor en caso de que éste caiga en esos vicios del lenguaje. En tal caso, Aristóteles recomienda observar si el adversario emplea palabras inusuales, y da como ejemplo precisamente algunos términos empleados por Platón en una de sus tragedias: "el ojo es ophryoskios, la araña viuda negra es sepsidácea o la médula es osteógena" ${ }^{38}$ Los términos extraños son: ỏф@vóoxıov, "sombreado

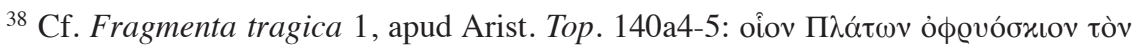

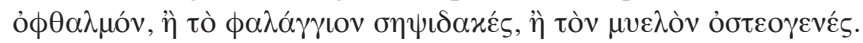




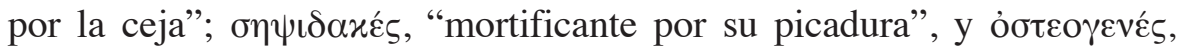
"producida en los huesos". Estas palabras son hapax legómena. Podemos pensar que el adversario tiene en este ejemplo la posibilidad de objetar el empleo de palabras oscuras. En caso de que Platón hubiera recurrido a palabras no comunes, también puede ser refutado en un diálogo trágico. A mi juicio, la importancia de los Tópicos aristotélicos no han sido tomados en consideración.

En el capítulo 4, Rossetti analiza con detenimiento el Eutifrón de Platón. ${ }^{39}$ El diálogo trata de un joven muy seguro de sí mismo, quien ha acudido a la sede del arconte-rey para iniciar un proceso contra su propio padre al que acusa de impiedad, y de Sócrates, que también acude al mismo lugar para responder a un citatorio con motivo de la acusación por impiedad iniciada por Méleto. Luego de algunos intercambios, Sócrates comienza un interrogatorio sobre el significado de la piedad, que el interlocutor no logra definir correctamente - desde el punto de vista de Sócrates - , hasta que se da por vencido y decide interrumpir el diálogo y propiamente huir del filósofo.

Rossetti pone al descubierto algunas estrategias macro-retóricas empleadas por el Sócrates platónico que se encuentran ocultas en el texto. A la primera definición que Eutifrón ofrece acerca de lo pío ("lo pío es lo que estoy por hacer en este momento [...]”, p. 170) el Sócrates de Platón se opone con la objeción de que se trata de un caso concreto de impiedad, pero no de lo pío en absoluto. Rossetti nota cómo Sócrates reduce y manipula la respuesta dada por Eutifrón, pues banaliza esa afirmación en vez de darle el peso que debe tener como "ejemplo ejemplar". Se puede observar que esa refutación y las siguientes son aceptadas acríticamente por los lectores de ayer y de siempre. Ello se debe a que Platón ha creado una situación en donde no sólo el interlocutor (Eutifrón) sino también los lectores están dispuestos a simpatizar y a aceptar la superioridad de Sócrates sobre su joven y presuntuoso interlocutor, dando crédito a las tesis de aquél y a dudar de las de éste y, en fin, a aceptar como legítimas las jugadas del protagonista. Observa L. Rossetti que, más allá de vivir

${ }^{39} \mathrm{El}$ ensayo se encuentra dividido en cinco secciones. Las tres primeras tienen la finalidad de definir el contexto histórico y textual para situar el diálogo; la cuarta describe la manera en que Platón manipula a sus lectores y la última muestra el rasgo distintivo del Eutifrón, que es la capacidad de la acumulación de resultados alcanzados durante la discusión y la introducción de nuevas adquisiciones (p. 189), lo que el autor denomina “extrema linealidad de la estructura" (p. 180). 
una emoción literaria, para acceder a los secretos del diálogo socrático, para interpretarlo libremente, es necesario liberarse de los condicionamientos y de la manipulación que se esconden tras el texto y establecer una distancia crítica frente al mismo, lo cual se logra sólo si se comprenden los mecanismos que nos llevan a tomar actitudes diferentes ante los protagonistas y ante sus afirmaciones.

Después de presentar el análisis anterior, Rossetti expone las características que distinguen al Eutifrón de otros diálogos aporéticos. En primer lugar señala "el extremo carácter lineal de la estructura" (p. 180), pero no logra identificar la lección del diálogo, porque ésta no existe; en cambio, ofrece "un paquete de mensajes" que recoge de otros diálogos aporéticos y los propone en bloque. Tal paquete incluye la presentación de una serie de ideas y la legitimación de un nuevo medio disciplinario que describe en términos generales (pp. 183-189). En seguida explica un aspecto distintivo del diálogo: la "capacidad de acumular las ganancias", que consiste en la introducción de nuevas precisiones, integración y refinamiento de las adquisiciones $\mathrm{y}$, al final, expone dos particularidades: el escepticismo en materia de religión olímpica y la supresión de la dimensión protréptica. En tercer lugar, observa que estos últimos aspectos permiten suponer que el diálogo fue escrito al final del periodo en que Platón escribió los diálogos aporéticos, donde el filósofo ya no se ve obligado a presentar a Sócrates como un defensor de la religión tradicional ni como impulsor de la vida filosófica:

la batalla en relación con Sócrates podía ser considerada ya como ganada y ello de una vez por todas, tanto que el autor no tenía ninguna necesidad de esforzarse en reivindicar sus méritos específicos e históricos, o su religiosidad fundamental a pesar de ciertas apariencias en contra, y que era posible utilizar más libremente su figura para hacer de ella el portavoz de las aspiraciones eminentemente cognitivas de su discípulo, sin temor de provocar el escándalo (p. 194).

De cualquier modo, el problema central del análisis es la descripción de los mecanismos que Sócrates emplea para lograr ofuscar y desorientar a su interlocutor, y sobre todo para obtener el consenso de nosotros los lectores del diálogo, sin que nos percatemos de las artimañas retóricas ocultas en el diálogo. 
Sócrates y el nacimiento del concepto de "filosofía" (Cap. 8)

De su meticuloso análisis de los diálogos socráticos Rossetti obtiene un resultado de la mayor importancia en la historia de la civilización occidental: en la última etapa de su vida el propio Sócrates se aplicó primero a sí mismo y luego a sus discípulos el calificativo de philósophos; al final, estos últimos se acostumbraron a llamarse a sí mismos con ese nombre para diferenciarse de los otros intelectuales a quienes aplicaron el nombre de sophistái en sentido peyorativo. El término philosophía indicaba "no la posesión de la sophía, sino un movimiento a la sophía [...] A Sócrates y sus discípulos les gustaba representarse como 'tendiendo a la sophía' ('amantes de la sabiduría')" (p. 276). Sólo cuando el interés en el diálogo había declinado y se consolidó la disposición a ofrecer las enseñanzas de manera explícita (y no en forma dialogada), lo que sucedió en especial con Aristóteles, se empezó a designar con el mismo término de philósophoi también a los autores de tratados llamados perí physeôs que habían vivido entre la segunda mitad del siglo vi y la mayor parte del siglo $\mathrm{V}$, aunque ellos no se denominaban a sí mismos como tales.

Para probar las afirmaciones anteriores, nuestro autor presenta un análisis del empleo de los términos philosophía y philósophos. Observa que, antes de la muerte de Sócrates (año 399 a. C.), el empleo de ambas palabras era muy limitado (menos de diez casos atestiguados), mientras que en los decenios siguientes su uso se incrementó de manera exponencial: 346 veces en Platón, 87 en Isócrates y 18 en Jenofonte). Analiza dos pasajes que han sido objeto de estudio sobre el origen y el desarrollo de ambos términos, ${ }^{40}$ y otros cinco que en general no se toman en consideración. ${ }^{41}$ Con base en el estudio de esos textos, se puede pensar que la noción de philosophía se encontraba íntimamente vinculada al diálogo socrático, una forma de comunicación altamente eficaz característica de Sócrates e imitada por sus discípulos, quienes la llenaban de contenido relativo a temas éticos y políticos. Del mismo modo, el maestro y sus seguidores emplearon la palabra philósophos para designarse a sí mis-

${ }^{40}$ Uno de Hipócrates $(V M, 20=$ Emp. 31A71 DK), y otro de Gorgias (Hell. $13=$ 82B11 DK).

${ }^{41}$ Tres de Platón (Euthid. 305c, Cham. 153d y Apol. 23d) y dos de Jenofonte (X. Mem. I.2.31 y Mem. I.6.2). 
mos, con el fin de identificar su particular costumbre de discutir con las personas y de diferenciarse de los demás pensadores, en particular de los sofistas y los maestros de retórica, como si fueran un solo grupo. ${ }^{42}$ Sólo cuando se diluyó la costumbre de elaborar diálogos, ya con Aristóteles - como he dicho arriba-, el término se empezó a utilizar también para designar a los pensadores presocráticos, quienes no se consideraban filósofos ni se designaban a sí mismos como tales.

Desde mi punto de vista, algunas ideas del resumen anterior merecen ser comentadas. El primero de ellos es que Rossetti no se aparta en ningún momento de la noción tradicional de philosophía (como "amor a la sabiduría"), sino que la reafirma. Sin embargo, noto en ello una ligera contradicción: el diálogo que se encuentra en el proceso de acceso al conocimiento no es el "diálogo socrático" en general, sino exclusivamente el diálogo aporético, que es sólo atribuible a Platón. Por tanto, no sería Sócrates y su círculo quienes utilizaron esa denominación, sino sólo y en última instancia Platón (excepto si el diálogo aporético no es exclusivo de Platón o si la finalidad de Sócrates y sus discípulos era el acceso al conocimiento).

Si la palabra tuvo desde su origen ese sentido, los ejemplos analizados por Rossetti permiten pensar que el único mérito de Sócrates y sus seguidores habría consistido en haber sido los primeros en designarse a sí mismo como filósofos. Los pasajes analizados por nuestro autor confirman lo anterior. Uno de ellos se encuentra en la Antigua medicina de Hipócrates ( $V M, 20=31$ a71 DK). Ahí se lee: "los médicos y los sofistas, cuyo logos tiende a la philosophía, como es el caso de Empédocles y otros, quienes han escrito sobre la arkhê, sobre lo que es el hombre, sobre su origen y composición". Señala Rossetti: la expresión es "signi-

${ }^{42}$ Rossetti afirma que "la tendencia a considerarse no como sofistas sino como rétores, que se manifestó en los intelectuales de formación sofística de los primeros decenios del siglo IV, no puede sino confirmar que la oposición filosofía versus sofística, se afirma a menudo con una victoria muy fácil de la primera sobre la segunda" (p. 271). Esto, sin embargo, no parece haber sido así, por lo menos en el caso de Isócrates, quien nunca emplea el término retórica. En Contra los sofistas (13), 21, utiliza la palabra @̇ enseñanza, sino para rechazarla: "Sin embargo, quienes desean obedecer los preceptos de esta filosofía [o enseñanza superior], podrían sacar mayor provecho para la equidad

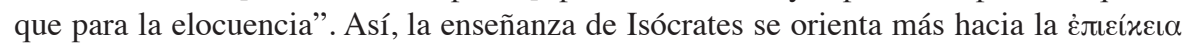
("equidad" o "sensatez") que hacia la oratoria. 
ficativa, pues revela que un profesional [esto es, Hipócrates] que no se considera a sí mismo filósofo, sabe (o presume saber) que el término en cuestión indica de manera adecuada un aspecto distintivo del saber desarrollado por Empédocles y otros intelectuales [...]", y concluye que "esta afirmación sería más pertinente si se encontrara un eco de ella en la forma en que Empédocles se presenta a sí mismo o en otras referencias al 'filósofo' de Acragas" (p. 266). Esta afirmación permite pensar que el término es empleado con claridad para referirse a Empédocles como filósofo fuera del círculo socrático y mucho antes de que Aristóteles hubiera empezado a escribir.

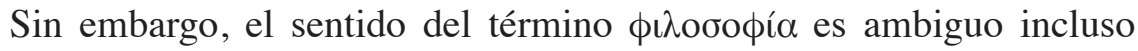
dentro de la obra platónica, y en el pasaje que nos ocupa, desde mi punto de vista, no tiene el significado (platónico) de "amor a la sabiduría", sino el de "conocimiento profundo" o "especializado" (cf. infra). De tal manera, en el pasaje en comento: (a) Hipócrates presenta a Empédocles como un médico o un sophistês mal orientado en lo que debe saber;

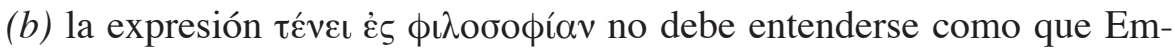
pédocles "tiende a la filosofía", sino que su logos, su razonamiento "aborda", "incluye" o "se extiende" a ese "conocimiento especializado". Si se prueba que eso significa precisamente en la literatura socrática, se fortalecería la hipótesis de que Sócrates y sus discípulos fueron los primeros en emplear esa palabra en el sentido de "amor a la verdad".

En otro pasaje (Gorg. Hel. 13) Gorgias observa que es necesario conocer los logoi de los meteorólogos, los debates mediante discursos

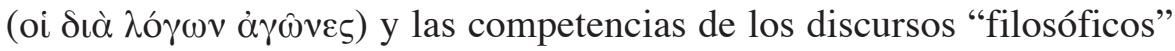

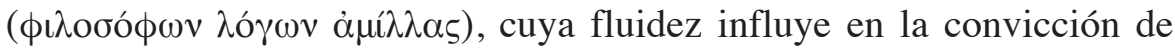

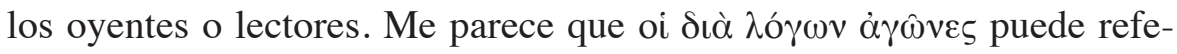
rirse a "los intercambios dialógicos" (incluyendo en este caso los deba-

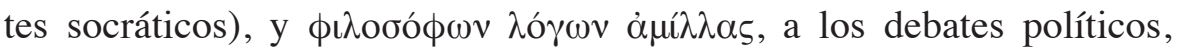

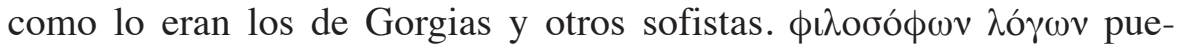
de tener el sentido de "razonamientos eficaces", esto es, discursos de hombres experimentados, sobre todo en el debate público. En efecto, Rossetti observa que "Todo permite pensar que el autor [esto es Gorgias] hace alusión a su propia virtuosidad y, más en general, a las de los sofistas" (pp. 266-267). Por tanto, tampoco este pasaje de Gorgias, datable hacia el 415, se referiría a los debates de los socráticos, y el término $\phi \iota \lambda o \sigma o ́ \phi \omega v$ no tendría aún el sentido especial con que fue utilizado por Sócrates y su escuela posteriormente: "la categoría del filósofo 
no estaría aún disponible en la época cuando Gorgias escribió su elogio" (p. 267). ${ }^{43}$

El sentido de philosophía en los demás testimonios es también discutible. En el Eutidemo (305c), Pródico se refiere a un tipo de personas que se encontraba a medio camino entre el philósophos y el político, declaración que podría haber sido emitida después del 399. Si los diálogos son ficticios, sería legítimo dudar de que realmente Pródico hubiera dicho lo que le atribuye Platón, pero, aunque así hubiera sido, philósophos pudo haber tenido un sentido diferente al que le asignaron los socráticos, algo así como "maestro renombrado de política". De cualquier modo, creo que con philósophos Platón podría estar aludiendo a Isócrates, quien se designaba a sí mismo philósophos y no intervenía en asuntos judiciales ni en el debate político. ${ }^{44}$

Hasta donde sé, los pasajes de Jenofonte (Mem. I.2.31) y de Platón (Apol., 23d) no habían sido suficientemente valorados. Según el primero, Critias habría hecho aprobar una ley que impedía enseñar el arte de la palabra, prohibición que tenía como blanco a Sócrates y a los filósofos. Según muestra Platón, algunos jóvenes interrogados por los Treinta lanzaban contra Sócrates las mismas acusaciones que acostumbraban lanzar contra los filósofos. Gracias a ambos pasajes se puede afirmar que "se tiene la impresión de que había ya cristalizado en la época de los Treinta una identidad colectiva bastante precisa, la de los filósofos, de la que Sócrates formaba parte a pleno título, pero cuya exclusividad no tenía" (p. 269). De tal manera, "Sócrates fue, según toda verosimilitud, el primer intelectual griego que se consideró y fue considerado filósofo en vida”. Ello se debió a que Sócrates y sus seguidores se identificaban a sí mismos filósofos, mientras que designaban a los demás pensadores

${ }^{43}$ Nuestro autor no analiza con detenimiento otros pasajes: Heraclit. 22B35 DK; Hdt. I.30.2; y no menciona el importante testimonio de Th. II 40.1, que indica claramente que la palabra philósophos está ya en uso, pero no tiene el sentido de "amor por la sabiduría".

${ }^{44}$ En el Cármides (153d) Sócrates pregunta: “¿Qué novedades hay en relación con la philosophía”. Como la fecha dramática de este diálogo es el 432 a. C., Rossetti observa: "es verosímil que la expresión refleje un fenómeno de proyección, dicho de otro modo, la antidatación de un uso lingüístico que se afirma en realidad algunos decenios más tarde" (p. 268). El reclamo de Antifonte contra Sócrates sobre la actividad de éste como filósofo (X. Mem. I.6.2) se puede explicar de la misma manera: se trata de un empleo del siglo IV que se atribuye al siglo anterior. Pero también puede tener un sentido diferente del de "amante de la sabiduría". 
contemporáneos de manera genérica como "sofistas", estableciendo así una dicotomía que se hizo fundamental en la historia de la filosofía.

No me parece que la identidad sea "bastante precisa". El pasaje de Jenofonte se refiere a una ley que prohibía enseñar el "arte de los discursos" ( $\lambda$ ó $\gamma \omega \nu \tau \varepsilon ́ \chi v \eta)$, pero no es claro que estuviera dirigida contra Sócrates, a quien se lanzaban los reproches que la multitud habitualmente dirigía contra los filósofos (de su mismo grupo). La expresión

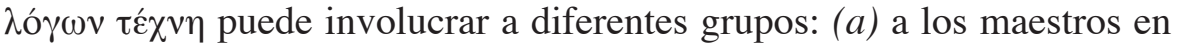
general, (b) a los maestros de política o sofistas, (c) a los filósofos en cuanto maestros de retórica y $(d)$ los filósofos en el sentido de maestros de dialéctica (esto es, los socráticos). Puede pensarse sobretodo que los destinatarios son los del primer grupo, pues el pasaje de Platón refiere que las acusaciones se hacían habitualmente "contra todos los filósofos" (Apol. 23d): sus ideas sobre el cielo y las cosas subterráneas, no creer en los dioses y hacer más fuerte el argumento más débil. De cualquier modo, no me parece que esos ataques se dirigieran en contra de Sócrates y su grupo, pues los jóvenes interrogados por los Treinta no sabían bien a bien de qué se acusaba al filósofo, y por ello le atribuían los insultos que se dirigían contra quienes se podría identificar como fisiólogos, ateos y maestros de retórica. Considero que en estos pasajes el término "filósofo" tiene un sentido muy general

Rossetti afirma que los sofistas "no habían deseado ser considerados como tales" (esto es, como filósofos, p. 273). No parece que esa afirmación sea del todo exacta. Como ejemplo de lo anterior, nuestro autor presenta el caso de Alcidamante, quien menciona la palabra philosophía "de manera fundamentalmente ocasional". Suponiendo que ello sea cierto, por desgracia nuestro autor no aborda el caso de Isócrates, que es más importante que cualquier otro, tanto desde un punto de vista cuantitativo como cualitativo.

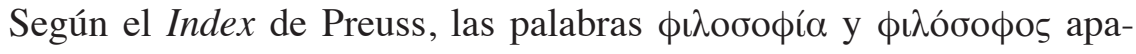
recen 91 veces en total en la obra de Isócrates. Con base en ese dato se puede afirmar que ese rhétor es uno de los escritores antiguos que emplea con mayor frecuencia ambas palabras, no sólo en relación con Jenofonte, sino incluso frente al propio Platón. La cifras son: Platón, 346 veces; Isócrates 91 (u 87, según Rossetti), de modo que la proporción es de 4 a 1 . Sin embargo, si tomamos en consideración las obras completas respectivas de ambos, esas palabras son proporcionalmente más frecuentes en Isócrates que en Platón. 
Por si ello fuera poco, se puede constatar que Isócrates se consideraba filósofo con mayor claridad que el propio Platón. Por ejemplo, en el discurso dedicado a Demónico (1), monarca chipriota joven aún, Isócrates afirma: "Tú anhelas educación y yo intento educar a los demás; tú estás en el mejor momento para filosofar y yo guío a quienes filosofan. ${ }^{45} \mathrm{El}$ pasaje más importante al respecto se encuentra en los parágrafos 180214 del Antídosis (15), donde Isócrates presenta de modo reiterado su

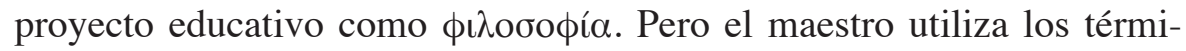
nos a los que aquí nos estamos refiriendo en el sentido que era habitual a principios del siglo IV, como "maestro superior" en el arte del razona-

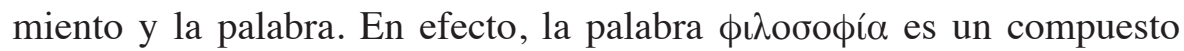
de dos palabra: фí̀os, que parece significar algo como "afición”, "cuidado", "propensión", y бoфía, "capacidad superior", "maestría” en una

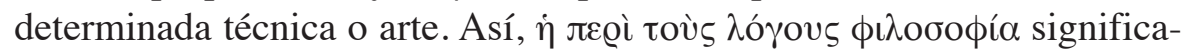
ría algo como "la preparación superior en razonamientos y palabras". En

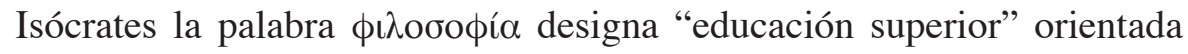
al estudio de la política, de modo que el pasaje del A Demónico podría traducirse de la siguiente manera: "tú estás en el mejor momento para adquirir una formación política superior y yo guío a quienes adquieren esa formación”.

De tal manera, se puede afirmar que: (a) el uso de las palabras фı фía y derivados no era propia de Sócrates y su círculo, (b) Isócrates empleaba esos términos con más frecuencia que los socráticos y en el sentido común y corriente en la antigüedad, y (c) la connotación de "amor por la sabiduría" es un sentido nuevo agregado por Platón (o tal vez Sócrates), que es el que ahora sigue en buena medida vigente. De esta manera, es inapropiado asignar a personajes como Protágoras y Gorgias el honroso título de filósofos, si entendemos esa palabra a la manera platónica y actual, pero es muy oportuno, si lo entendemos en el sentido que era común y corriente en el siglo IV. Por desgracia, el problema es que hoy ya nadie emplea la palabra $\phi \iota \lambda$ oбoфía en el sentido original de "formación superior".

De cualquier modo, los comentarios anteriores no refutan las hipótesis principales: Sócrates y los socráticos pueden considerarse como practicantes y maestros de un saber retórico sumamente eficaz, capaz de obnu-

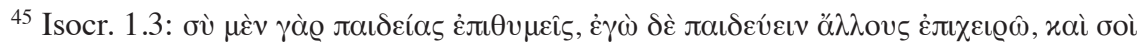

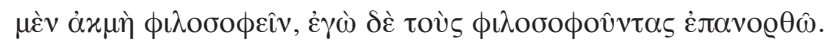


bilar las mentes de los lectores contemporáneos y del público universal, incluidos aquellos expertos que se dedican al estudio de la filosofía griega. Se puede afirmar que Livio Rossetti encontró la clave de lectura que permite resolver uno de los grandes enigmas de la filosofía: la cuestión socrática. Logró lo anterior mediante la aplicación de una metodología empleada por los socráticos que había permanecido oculta al escrutinio de los estudiosos: las estrategias macro-retóricas. 